\title{
Efficacy and Safety of Once-Weekly Dulaglutide in Elderly Chinese Patients with Type 2 Diabetes: A Post Hoc Analysis of AWARD-CHN Studies
}

\author{
Jian Kuang · Jiankun Zhu · Siying Liu · Quanmin Li
}

Received: July 22, 2020 / Published online: August 28, 2020

(C) The Author(s) 2020

\section{ABSTRACT}

Introduction: This analysis evaluated the efficacy and safety of dulaglutide in Chinese patients with type 2 diabetes (T2D) aged $\geq 60$ and $<60$ years.

Methods: This post hoc analysis included patients with T2D enrolled in two phase 3 clinical trials AWARD-CHN1 (NCT01644500) and AWARD-CHN2 (NCT01648582) of dulaglutide 0.75 and $1.5 \mathrm{mg}$. Patients were

Digital Features To view digital features for this article go to https://doi.org/10.6084/m9.figshare.12801050.

Electronic supplementary material The online version of this article (https://doi.org/10.1007/s13300020-00910-1) contains supplementary material, which is available to authorized users.

J. Kuang

Department of Endocrinology, Guangdong

Provincial People's Hospital, Guangdong Academy

of Medical Sciences, Guangzhou, China

J. Kuang

The Second School of Clinical Medicine, Southern

Medical University, Guangzhou, China

J. Zhu · S. Liu ( $\square)$

Lilly Suzhou Pharmaceutical Co. Ltd, Shanghai,

China

e-mail: liu_si_ying@lilly.com

Q. Li $(\square)$

PLA Rocket Force Characteristic Medical Center, Beijing, China

e-mail: liqm0806@163.com categorized into two groups $(\geq 60$ and $<60$ years). Efficacy outcomes (change in glycated hemoglobin [HbA1c], fasting blood glucose [FBG], and weight; percentage of patients achieving HbA1c target $[<7.0 \%]$ ) and safety outcomes (incidence of hypoglycemia and gastrointestinal treatment-emergent adverse events [GI TEAEs]) at 26 weeks were evaluated for each age group in both trials.

Results: A total of 766 patients ( $\geq 60$ years, $n=222$; $<60$ years, $n=544$ ) were included in the study. A similar reduction of HbA1c was observed in both age groups: AWARD-CHN1, $1.5 \mathrm{mg}$ (least squares mean [LSM] 95\% confidence interval $[\mathrm{CI}] \geq 60$ years: $-1.45 \%[-1.69$, $-1.21 \%]$ and < 60 years: $-1.43 \%$ [- 1.59 , $-1.28 \%]$ ) and $0.75 \mathrm{mg}$ ( $\geq 60$ years: $-1.29 \%$ $[-1.53,-1.05 \%]$ and < 60 years: $-1.18 \%$ $[-1.33,-1.03 \%]) ; \quad$ AWARD-CHN2, $1.5 \mathrm{mg}$ ( $\geq 60$ years: $-1.60 \%[-1.83,-1.36 \%]$ and $<60$ years: $-1.64 \%[-1.80,-1.49 \%])$ and $0.75 \mathrm{mg} \quad(\geq 60$ years: $-1.31 \% \quad[-1.55$, $-1.08 \%]$ and < 60 years: $-1.33 \%$ [- 1.48 , $-1.17 \%]$ ). Dulaglutide showed a reduction in HbA1c as early as 4 weeks after initiation of treatment, which was maintained over 26 weeks in both age groups. The percentage of patients achieving HbA1c target $<7.0 \%$ at 26 weeks was also similar in both age groups. Incidence of hypoglycemia and GI TEAEs was low in each age group. 
Conclusion: Treatment with once-weekly dulaglutide improved glycemic control in patients with T2D aged $\geq 60$ years and $<60$ years and was well tolerated in older patients, suggesting it can be considered a safe and effective treatment option for use in older patients with T2D.

Trial registration: AWARD-CHN1 (NCT016 44500) and AWARD-CHN2 (NCT01648582).

Keywords: Age; Dulaglutide; GLP-1 receptor agonist; Subgroup analysis; Type 2 diabetes; $\beta$ cell function

\section{Key Summary Points}

Why carry out this study?

Type 2 diabetes (T2D) is increasing at an alarming rate in geriatric populations, and treatment in these patients is complex because of comorbidities and functional impairments, and a high risk of adverse events such as recurring hypoglycemia.

Glucagon-like peptide 1 (GLP-1) receptor agonists (RAs) are considered a good therapy for the elderly patients with diabetes owing to its low risk of hypoglycemia.

The present study is a post hoc analysis of AWARD-CHN1 and AWARD-CHN2 to evaluate efficacy and safety of onceweekly dulaglutide ( 1.5 and $0.75 \mathrm{mg}$ ) in patients with T2D aged $\geq 60$ and $<60$ years.

\section{What was learned from the study?}

The study indicated a similar change in HbA1c, FBG, and weight reduction and increased proportion of patients achieving HbA1c target $(<7 \%)$ in Chinese patients in both age groups ( $\geq 60$ and $<60$ years). Incidence of GI TEAEs and hypoglycemia were low.
The overall findings from the present study demonstrate improvement of glycemic control and tolerability of onceweekly dulaglutide in patients aged $\geq 60$ and $<60$ years.

\section{DIGITAL FEATURES}

This article is published with digital features to facilitate understanding of the article. You can access the digital features on the article's associated Figshare page. To view digital features for this article go to https://doi.org/10.6084/m9. figshare. 12801050.

\section{INTRODUCTION}

Diabetes mellitus has been rising at an alarming rate worldwide with the prevalence in adults (20-79 years) at $9.3 \%$ (463 million) in 2019 , and it is estimated that it will be approximately $10.2 \%$ (578 million) by 2030 and $10.9 \%$ (700 million) by 2045 [1], of which type 2 diabetes (T2D) accounts for 90-95\% [2]. In 2019, China had the highest number of adults with diabetes (116.4 million) and is anticipated to remain so in 2030 and 2045 [3].

An aging population contributes to the increased prevalence of diabetes, with a prevalence at $20.2 \%$ in over 60 -year-olds in China [4]. Aging is also associated with many comorbidities such as cognitive dysfunction, neuropathy, renal impairment, and high-risk adverse events such as recurring hypoglycemia. The utility of some therapies, including insulin and sulfonylureas, is limited in geriatric populations by the risk of hypoglycemia $[5,6]$.

Glucagon-like peptide 1 (GLP-1) receptor agonists (RAs) enhance insulin secretion and suppress glucagon secretion in a glucose-dependent manner [7] and impart low risk of hypoglycemia [8] and could be considered for the management of glycemic control in older people with T2D with either previous cardiovascular disease or cardiovascular risk factors [9]. Dulaglutide, a once-weekly GLP-1RA 
approved for treatment of T2D in China, has been reported to be beneficial in Chinese patients with T2D in two phase 3 trials (AWARD-CHN1 and AWARD-CHN2) [10, 11].

The present post hoc analysis aimed to investigate the efficacy and safety of dulaglutide in Chinese patients with T2D aged $\geq 60$ years and $<60$ years and to provide evidence for the older population with T2DM when using dulaglutide in clinical practice for Chinese patients.

\section{METHODS}

\section{Study Design and Patients}

The post hoc analysis of AWARD-CHN1 (NCT01644500) and AWARD-CHN2 (NCT01648582) only included the Chinese subpopulation which was stratified by baseline age. The study design of AWARD-CHN studies was published in detail previously $[12,13]$. AWARDCHN1 was a double-blind, multicenter, randomized, phase 3 study to compare the efficacy and safety of dulaglutide with glimepiride monotherapy, and AWARD-CHN2 was an openlabel, multicenter, randomized, non-inferiority phase 3 study to compare the efficacy and safety of dulaglutide with insulin glargine add-on to metformin and/or sulfonylurea.

Patients in each trial were categorized into two groups based on age at baseline, $\geq 60$ and $<60$ years, following Chinese Diabetes Society guidance that considers geriatrics as 60 years and older [14]. With the development of diabetes, lower $\beta$-cell function advances with aging, so patients were also categorized into tertiles based on baseline $\beta$-cell function [Updated Homeostasis Model Assessment of $\beta$-cell function (HOMA2-\%B)].

This study is a post hoc analysis of primary publications $[12,13]$. Both studies were initiated after approval of the study protocol by the ethics review board at each site including the master ethics review board at Ruijin Hospital Affiliate to Shanghai Jiao Tong University, and written informed consent was obtained from all patients. All procedures followed ethical standards, and the study was conducted in accordance with 1964 declaration of Helsinki and its amendments, Good Clinical Practice guidelines, and applicable local laws and regulations.

\section{Study Outcomes}

Efficacy outcomes included change in glycated hemoglobin (HbA1c), fasting blood glucose (FBG), and body weight from baseline to week 26; percentage of patients achieving $<7 \% \mathrm{HbA} 1 \mathrm{c}$ at week 26; and change in HbA1c over time.

Safety outcomes included the incidence of hypoglycemia and gastrointestinal treatmentemergent adverse events (GI TEAEs), which were the most common TEAEs observed in AWARD-CHN1 and AWARD-CHN2 [10, 11].

\section{Statistical Analysis}

Baseline data were compared with post-treatment data at week 26 . The efficacy analysis was conducted on the modified intention-to-treat population. This included all randomized patients that received at least one dose of the study drug and had one baseline HbA1c measurement along with at least one post-baseline HbA1c measurement. Changes in HbA1c, FBG, and weight from baseline to 26 weeks were estimated by least-squares mean (LSM) and the corresponding 95\% confidence interval (CI) using analysis of covariance (ANCOVA). Counts and percentages were used to summarize categorical data whereas mean, standard deviation, and median were used to summarize continuous data. Safety was assessed in terms of incidence of hypoglycemia and GI TEAEs in the safety population who received at least one dose of the study drug. SAS version 9.3 was used to perform all analyses.

\section{RESULTS}

\section{Patients Characteristics}

A total of 766 patients [age $\geq 60$ years, $n=106$ (AWARD-CHN1) and $n=116$ (AWARD-CHN2); age $<60$ years, $n=264$ (AWARD-CHN1) and $n=280$ (AWARD-CHN2)] were included in the study. Of these 766 patients, 384 received 


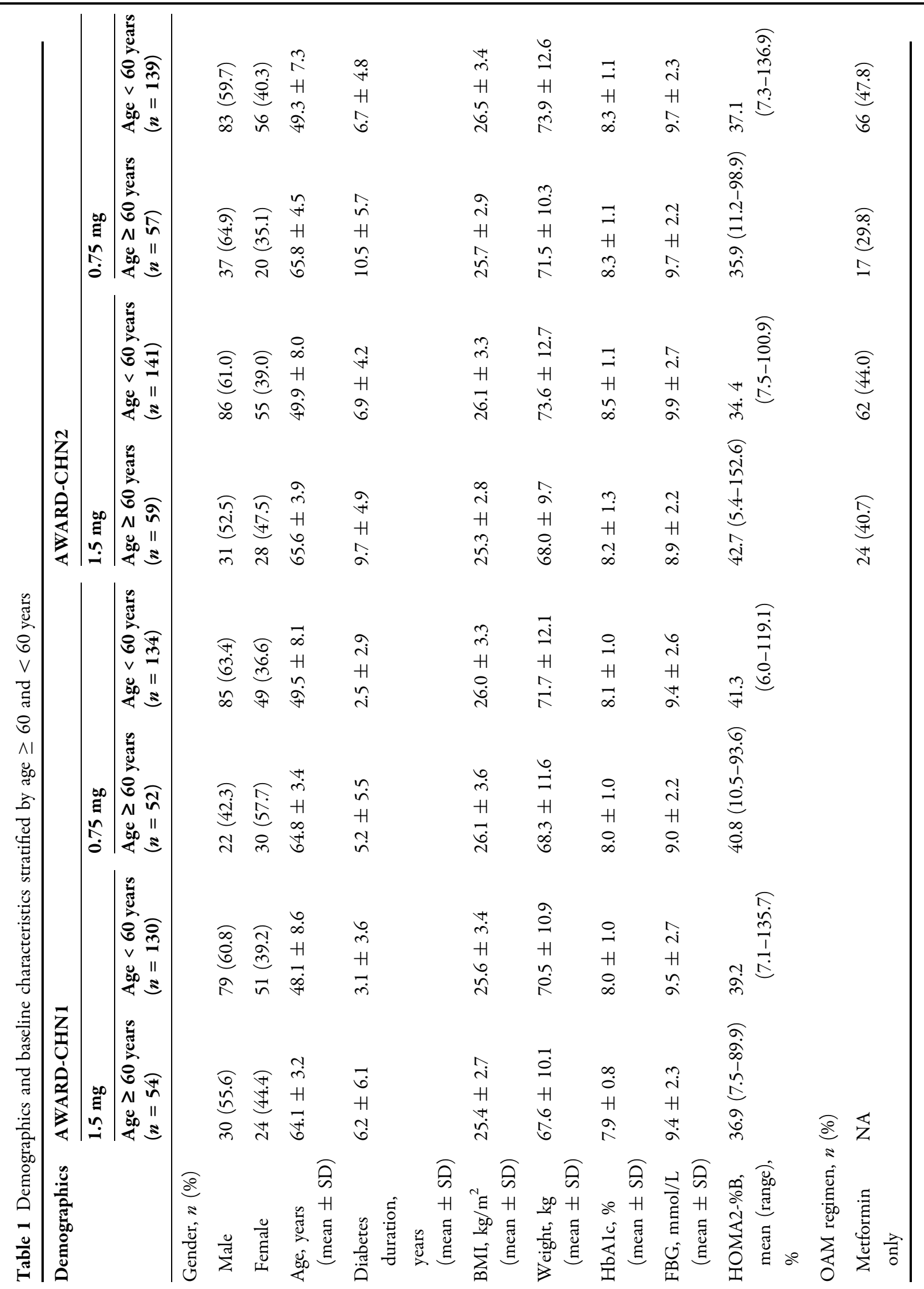




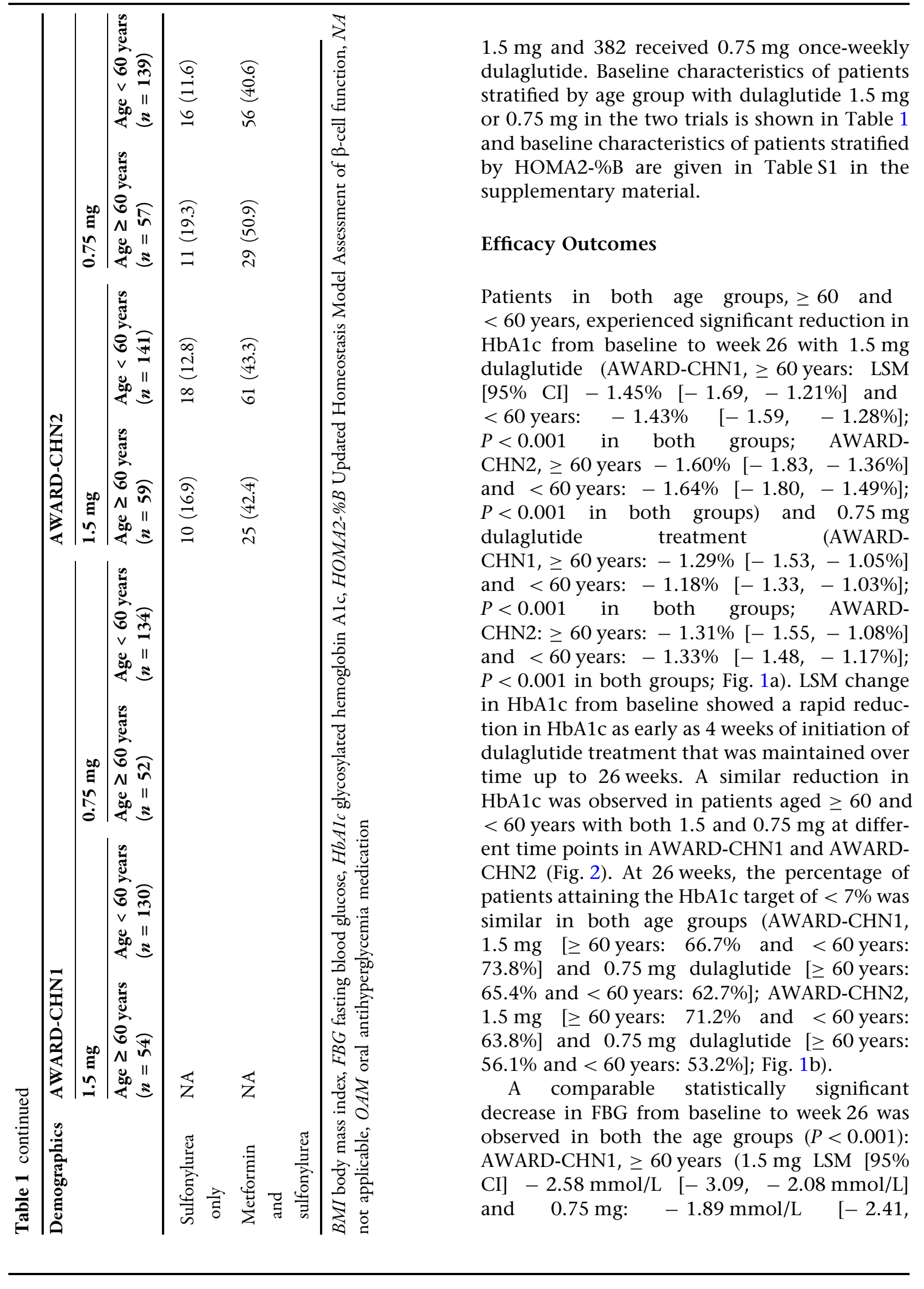


A
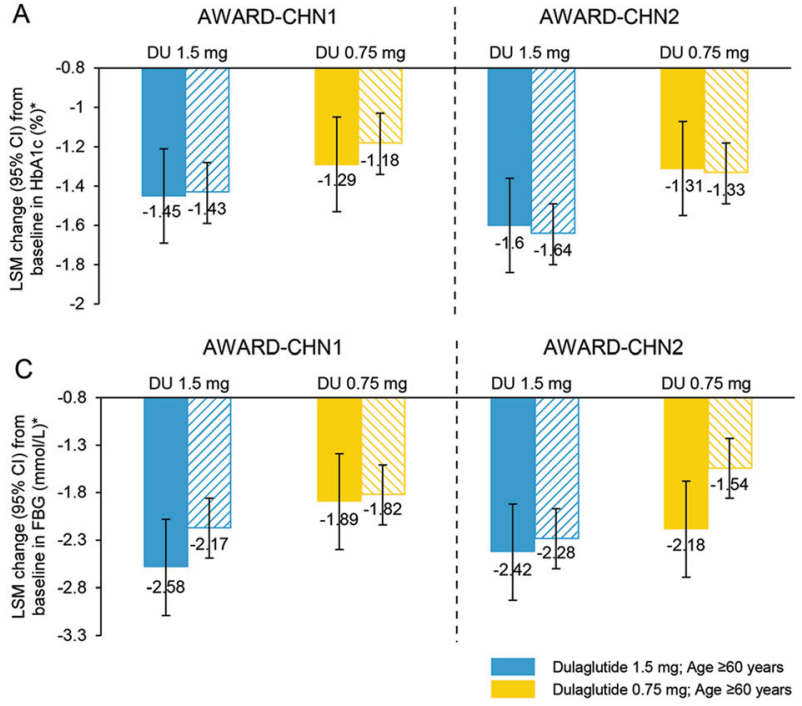

Fig. 1 Efficacy outcomes of dulaglutide in patients aged $\geq 60$ and $<60$ years. a Change in HbAlc from baseline to week 26; b percentage of patients achieving HbAlc

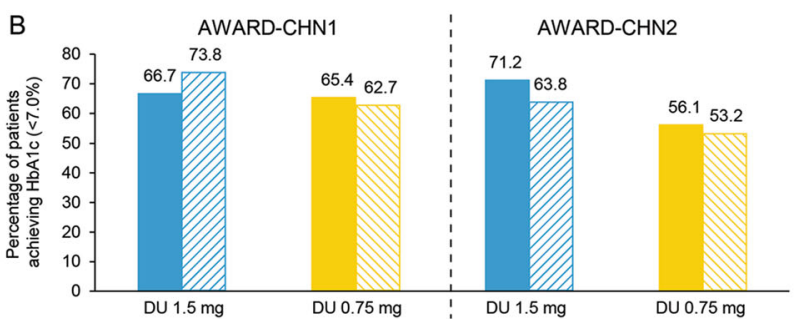

$\begin{array}{lll}D & \text { AWARD-CHN1 } & \text { AWARD-CHN2 }\end{array}$

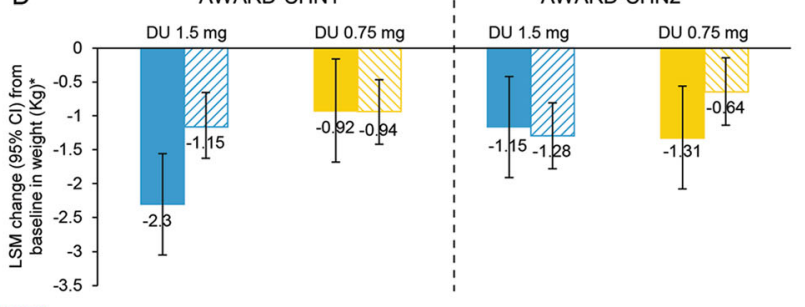

Dulaglutide $1.5 \mathrm{mg}$; Age $<60$ years

Dulaglutide $0.75 \mathrm{mg}$; Age $<60$ years

target $(<7.0 \%)$ at week 26; c change in FBG from baseline to week 26 ; $\mathbf{d}$ change in weight from baseline to week 26

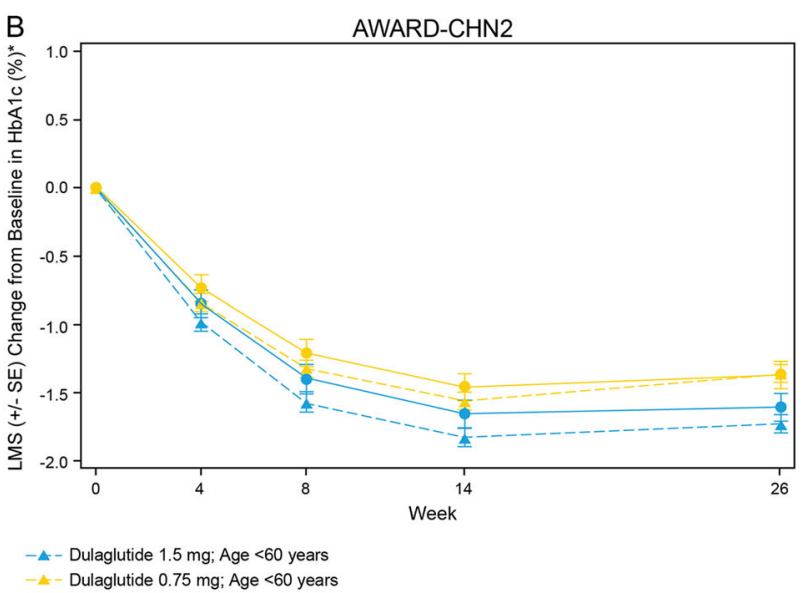

Fig. 2 Change in HbAlc from baseline to week 26 over time stratified by age $\geq 60$ and $<60$ years. a AWARD-CHN1; b AWARD-CHN2

$-1.37 \mathrm{mmol} / \mathrm{L}])$ and < 60 years (1.5 mg:

$-2.17 \mathrm{mmol} / \mathrm{L}[-2.49,-1.86 \mathrm{mmol} / \mathrm{L}]$ and

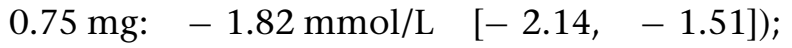
AWARD-CHN2, $\geq 60$ years:

(1.5 mg: $-2.42 \mathrm{mmol} / \mathrm{L}[-2.95,-1.88 \mathrm{mmol} / \mathrm{L}]$ and $0.75 \mathrm{mg}:-2.18 \mathrm{mmol} / \mathrm{L}[-2.72,-1.64 \mathrm{mmol} /$ $\mathrm{L}]$ and < 60 years $(1.5 \mathrm{mg}$ : $-2.28 \mathrm{mmol} / \mathrm{L}$ $[-2.63,-1.93 \mathrm{mmol} / \mathrm{L}]$ and $0.75 \mathrm{mg}$ : $-1.54 \mathrm{mmol} / \mathrm{L} \quad[-1.90, \quad-1.19 \mathrm{mmol} / \mathrm{L}]$; Fig. 1c). In addition, a statistically significant reduction in body weight was observed from baseline to week 26 in patients of both the age groups with two doses of dulaglutide in AWARD-CHN1 and AWARD-CHN2 $(P<0.05$; Fig. 1d).

Further analysis of efficacy in patients stratified by baseline $\beta$-cell function tertile showed that the reductions of HbA1c and FBG were significant in each of the low, middle, and high $\beta$-cell function group $(P<0.05)$. The percentage of patients achieving HbA1c target of $<7 \%$ was $53.2-56.1 \%$ even in the low $\beta$-cell function 
group with $1.5 \mathrm{mg}$ dulaglutide in the two trials. Weight reduction in each group was also observed and is shown in Fig. S1 of the supplementary material. A similar reduction in HbA1c was observed from baseline at week 4, 8, 14, and 26 that was maintained over time in low, middle, and high $\beta$-cell function groups (Fig. S2 of the supplementary material).

\section{Safety Outcomes}

The incidence of total hypoglycemia was as follows: AWARD-CHN1, $1.5 \mathrm{mg}$ ( $\geq 60$ years: $1.8 \%$ and < 60 years: $7.5 \%)$ and $0.75 \mathrm{mg}$ dulaglutide ( $\geq 60$ years: $3.8 \%$ and $<60$ years: $3.6 \%)$ AWARD-CHN2, $1.5 \mathrm{mg} \quad(\geq 60$ years: $20.0 \%$ and $<60$ years: $14.0 \%)$ and $0.75 \mathrm{mg}$ dulaglutide ( $\geq 60$ years: $21.7 \%$ and $<60$ years: 12.8\%; Fig. 3). No severe hypoglycemia events were observed in both trials.

Incidences of GI TEAEs reported in $\geq 1 \%$ patients are represented in Fig. 4. Similar incidences of GI TEAEs were reported in both the age groups for $1.5 \mathrm{mg}$ (incidence of $\geq 1 \%$ GI TEAE in AWARD-CHN1: $39.3 \%$ and $36.1 \%$ in patients aged $\geq 60$ and $<60$ years, respectively; AWARD-CHN2: $33.3 \%$ and $30.8 \%$ in patients aged $\geq 60$ and $<60$ years, respectively) and $0.75 \mathrm{mg}$ dulaglutide treatment (incidence of $\geq 1 \%$ GI TEAE in AWARD-CHN2: $28.3 \%$ and $24.1 \%$ in patients aged $\geq 60$ years and $<60$ years, respectively). The most frequent GI- related adverse event was diarrhea; detailed incidence of GI TEAEs are listed in Fig. 4.

\section{DISCUSSION}

In this post hoc analysis of AWARD-CHN1 and AWARD-CHN2 trials, treatment with onceweekly dulaglutide demonstrated clinically relevant $\mathrm{HbA1c}$, FBG, and weight reduction and led to increased proportions of Chinese patients with T2D aged $\geq 60$ and $<60$ years achieving HbA1c target $(<7 \%)$, and the efficacy of glycemic control was not influenced by baseline $\beta$ cell function.

In accordance with previous reports reviewing a pooled analysis of six trials, the present study showed similar effectiveness of glycemic control and safety profiles irrespective of baseline age [5]. Other GLP1-RAs such as liraglutide and exenatide also reported effective glycemic control irrespective of baseline age. Bode et al. reported that liraglutide was well tolerated in all patients irrespective of age with low hypoglycemic risk, and suggested it as a suitable option for geriatric patients with comorbidities [15]. Pencek et al. reported the tolerability of exenatide regardless of age in all patients [16]. The results of the present study were in accordance with other GLP-1RAs.

In the AWARD-CHN1 $1.5 \mathrm{mg}$ group, weight reduction in patients $\geq 60$ years was greater than in patients $<60$ years, although in

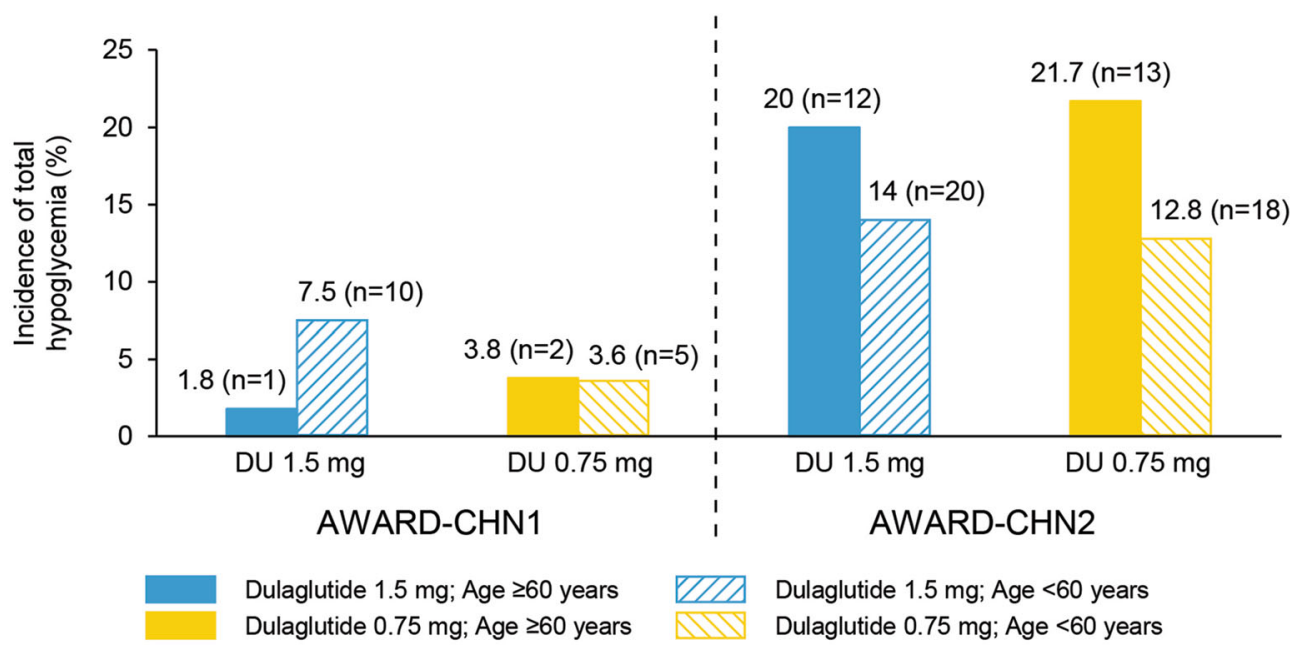

Fig. 3 Incidence of hypoglycemia $[\%(n)]$ through 26 weeks overall stratified by age $\geq 60$ years and age $<60$ years 

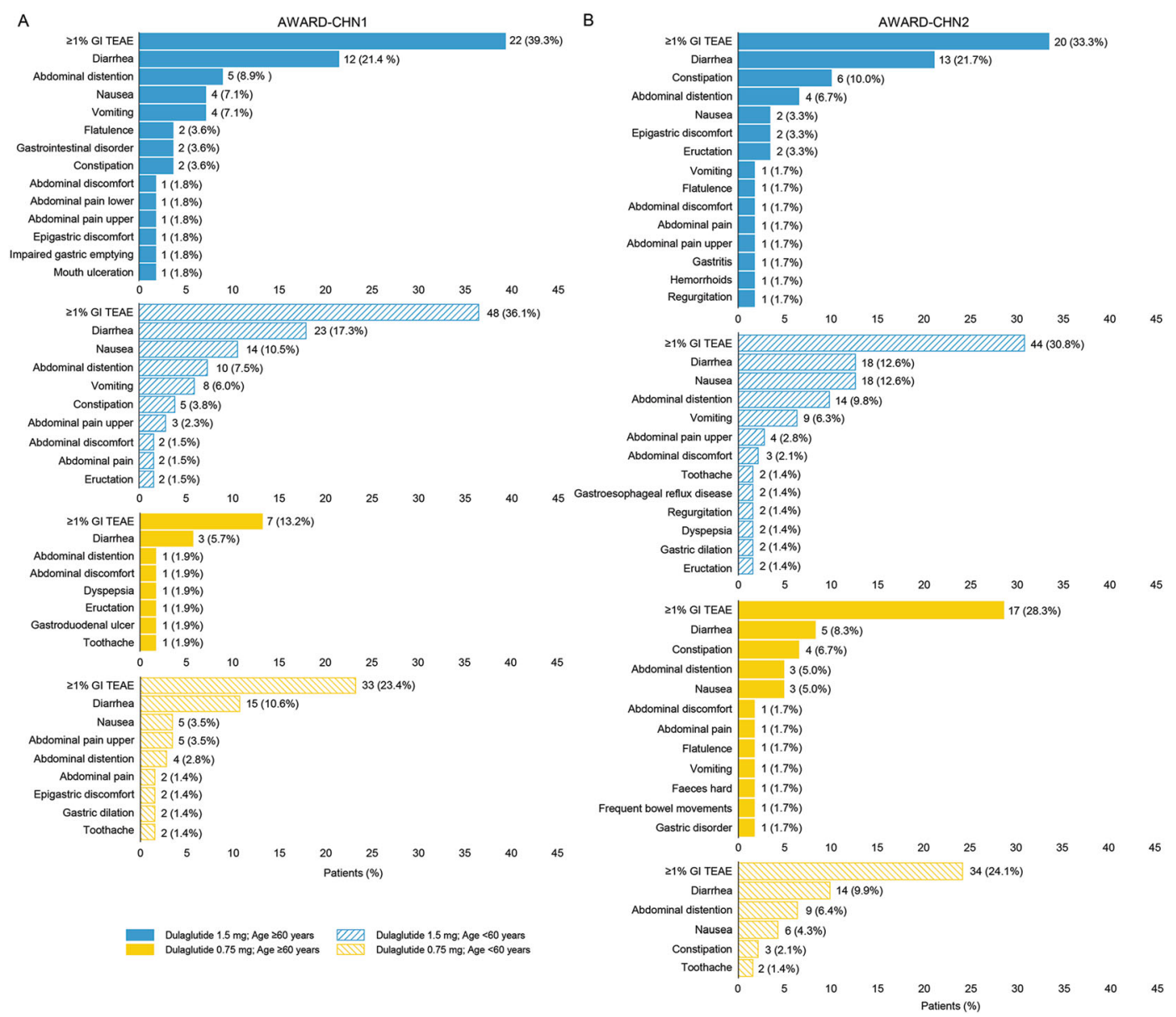

Fig. 4 Gastrointestinal treatment-emergent adverse events reported in $\geq 1 \%$ patients through 26 weeks overall by aged $\geq 60$ and $<60$ years $[n(\%)]$. a AWARD-CHN1; b AWARD-CHN2

AWARD-CHN2 weight reduction was similar between age groups. While there is not a clear rationale for the observation, dulaglutide was well tolerated in both age groups and weight reduction was within the acceptable range. A pooled analysis of dulaglutide stratified by age reported similar weight loss in both the age groups ( $<65$ and $\geq 65$ years) [5].

A decrease in $\beta$-cell function with aging has been reported [17]; however, modulation of insulin secretion from $\beta$-cells in a glucose-dependent manner is one of the mechanisms of controlling glycemic levels by GLP-1RAs $[18,19]$. The analysis of the effect of baseline $\beta$ cell function on dulaglutide efficacy in this study indicates that glycemic control was not influenced by baseline $\beta$-cell function, which is consistent with reported studies stating that once-weekly dulaglutide improved glycemic control irrespective of $\beta$-cell function [20].

Recently, GLP-1RAs have been recommended by the American Diabetes Association (ADA) as preferred over insulin in older adults with T2D at increased risk of hypoglycemia because meta-analyses [21-24] suggest lower risk of hypoglycemia and benefit of weight loss. Generally, few patients $(\leq 6[3.2 \%]$ in each dose treatment group) discontinued treatment as a result of AEs in AWARD-CHN1 and AWARDCHN2 $[10,11]$. The incidence of hypoglycemia was low in both AWARD-CHN1 and AWARDCHN2. It is a little higher in AWARD-CHN2, which may be related to oral antihyperglycemic medication background use (i.e., metformin and/or sulfonylurea) in AWARD-CHN2 patients, suggesting that administration of 
dulaglutide with metformin and/or sulfonylurea may increase incidence of hypoglycemia in clinical practice in the older population. Dulaglutide was well tolerated in Chinese patients, and the incidence of TEAEs was generally low [10, 11]. GI TEAEs are the most common AEs in patients using GLP-1RAs, and in accordance, this analysis shows that GI adverse events, particularly diarrhea, were the most common TEAEs in the present study [25]. However, the incidence of diarrhea is similar with other GLP-1RAs [26] and is similar regardless of age and dose in this analysis. As per dulaglutide prescribing information, no dose adjustment is required on the basis of age; the results of present study also represent the same.

The present post hoc subgroup analysis has certain limitations of evidence but provides input for clinical practice. The baseline age range was limited to $\geq 60$ years; however, the percentage of patients aged $\geq 75$ years was small in these two trials. In addition, the duration of this study was limited to 26 weeks, which may not represent the effects of longterm use of dulaglutide.

\section{CONCLUSION}

Our findings indicate that treatment with onceweekly dulaglutide improves glycemic control even in patients aged $\geq 60$ years and in lower baseline $\beta$-cell function groups. Dulaglutide was well tolerated in elderly patients, suggesting that dulaglutide can be considered a safe and effective treatment option for use in geriatric patients with T2D.

\section{ACKNOWLEDGEMENTS}

Funding. The study and the journal's rapid service fee were funded by Eli Lilly (Shanghai, China).

Authorship. All named authors meet the International Committee of Medical Journal Editors (ICMJE) criteria for authorship for this article, take responsibility for the integrity of the work as a whole, and have given their approval for this version to be published.

Authorship Contributions. Siying Liu was involved in conception, design, and interpretation of data. Jiankun Zhu was involved in analysis of data and interpretation of data. Jian Kuang and Quanmin $\mathrm{Li}$ were involved in acquisition and interpretation of data.

Medical Writing, Editorial, and Other Assistance. The authors would like to acknowledge Dr. Yunjing Zhang (Lilly Suzhou Pharmaceutical Co. Ltd) for medical writing, medical review and project management, and Dr. Satya Lavanya Jakki and Dr. Anuradha Nalli (Indegene Pvt Ltd) for medical writing and editorial support.

Prior Presentation. An abstract and poster of this study were presented at the Chinese Diabetes Society 23rd Scientific Meeting, held on November 20-23, 2019 in Xiamen, China.

Disclosures. Siying Liu and Jiankun Zhu are employees of Eli Lilly and Company. Jian Kuang has received honoraria for attending meetings, consultancy fees, speaker fees for Eli Lilly and Company. Quanmin Li has nothing to disclose.

Compliance with Ethics Guidelines. This study is a post hoc analysis of primary publications $[12,13]$. Both studies were initiated after approval of the study protocol by the ethics review board at each site including the master ethics review board at Ruijin Hospital Affiliate to Shanghai Jiao Tong University. All procedures followed were in accordance with the ethical standards of the responsible committees on human experimentation (institutional and national) and with the Helsinki Declaration of 1964, as revised in 2013, and Good Clinical Practice. Written informed consent was obtained from all patients before participation.

Data Availability. The datasets generated and analyzed during the current study are not broadly publicly available to respect company confidentiality but may be available from the corresponding author on reasonable request. 
Open Access. This article is licensed under a Creative Commons Attribution-NonCommercial 4.0 International License, which permits any non-commercial use, sharing, adaptation, distribution and reproduction in any medium or format, as long as you give appropriate credit to the original author(s) and the source, provide a link to the Creative Commons licence, and indicate if changes were made. The images or other third party material in this article are included in the article's Creative Commons licence, unless indicated otherwise in a credit line to the material. If material is not included in the article's Creative Commons licence and your intended use is not permitted by statutory regulation or exceeds the permitted use, you will need to obtain permission directly from the copyright holder. To view a copy of this licence, visit http://creativecommons.org/licenses/by$\mathrm{nc} / 4.0 /$.

\section{REFERENCES}

1. Saeedi P, Petersohn I, Salpea P, et al. Global and regional diabetes prevalence estimates for 2019 and projections for 2030 and 2045: results from the International Diabetes Federation Diabetes Atlas, 9th edition. Diabetes Res Clin Pract. 2019;157: 107843.

2. Wu Y, Ding Y, Tanaka Y, Zhang W. Risk factors contributing to type 2 diabetes and recent advances in the treatment and prevention. Int J Med Sci. 2014;11:1185-200.

3. IDF Diabetes Atlas, 9th edn. (2019). https://www. idf.org/diabetesatlas.

4. Wang L, Gao P, Zhang M, et al. Prevalence and ethnic pattern of diabetes and prediabetes in China in 2013. JAMA. 2017;317:2515-23.

5. Boustani MA, Pittman I, Yu M, Thieu VT, Varnado OJ, Juneja R. Similar efficacy and safety of onceweekly dulaglutide in patients with type 2 diabetes aged $\geq 65$ and $<65$ years. Diabetes Obes Metab. 2016;18:820-8.

6. Morley JE, Abbatecola AM, Woo J. Management of comorbidities in older persons with type 2 diabetes. J Am Med Dir Assoc. 2017;18:639-45.
7. Nauck MA. Incretin-based therapies for type 2 diabetes mellitus: properties, functions, and clinical implications. Am J Med. 2011;124:S3-18.

8. Kirkman MS, Briscoe VJ, Clark N, et al. Diabetes in older adults: a consensus report. J Am Geriatr Soc. 2012;60:2342-56.

9. Gerstein HC, Colhoun HM, Dagenais GR, et al. Dulaglutide and cardiovascular outcomes in type 2 diabetes (REWIND): a double-blind, randomised placebo-controlled trial. Lancet. 2019;394:121-30.

10. Shi LX, Liu XM, Shi YQ, et al. Efficacy and safety of dulaglutide monotherapy compared with glimepiride in Chinese patients with type 2 diabetes: post-hoc analyses of a randomized, double-blind, phase III study. J Diabetes Investig. 2020;11:142-50.

11. Li Y, Li L, De Peng Y, Song GY, et al. Efficacy and safety of dulaglutide versus insulin glargine in Chinese T2DM patients: a subgroup analysis of a randomized trial (AWARD-CHN2). Diabetes Ther. 2019;10:1435-52.

12. Chen YH, Huang C-N, Cho YM, et al. Efficacy and safety of dulaglutide monotherapy compared with glimepiride in East-Asian patients with type 2 diabetes in a multicentre, double-blind, randomized, parallel-arm, active comparator, phase III trial. Diabetes Obes Metab. 2018;20:2121-30.

13. Wang W, Nevárez L, Filippova E, et al. Efficacy and safety of once-weekly dulaglutide versus insulin glargine in mainly Asian patients with type 2 diabetes mellitus on metformin and/or a sulphonylurea: a 52-week open-label, randomized phase III trial. Diabetes Obes Metab. 2019;21:234-43.

14. Chinese Diabetes Society. China guideline for type 2 diabetes (2017). Chin J Diabetes Melitus. 2018;10:4-67.

15. Bode BW, Brett J, Falahati A, Pratley RE. Comparison of the efficacy and tolerability profile of liraglutide, a once-daily human GLP-1 analog, in patients with type 2 diabetes $\geq 65$ and $<65$ years of age: a pooled analysis from phase III studies. Am J Geriatr Pharmacother. 2011;9:423-33.

16. Pencek R, Blickensderfer A, Li Y, Brunell SC, Chen S. Exenatide once weekly for the treatment of type 2 diabetes: effectiveness and tolerability in patient subpopulations: exenatide once weekly for the treatment of type 2 diabetes. Int J Clin Pract. 2012;66:1021-32.

17. De Tata V. Age-related impairment of pancreatic beta-cell function: pathophysiological and cellular mechanisms. Front Endocrinol. 2014;5:138. 
18. Home PD, Shamanna P, Stewart M, et al. Efficacy and tolerability of albiglutide versus placebo or pioglitazone over 1 year in people with type 2 diabetes currently taking metformin and glimepiride: HARMONY 5. Diabetes Obes Metab. 2015;17: 179-87.

19. Prasad-Reddy L, Isaacs D. A clinical review of GLP-1 receptor agonists: efficacy and safety in diabetes and beyond. Drugs Context. 2015;4:212283.

20. Mathieu C, Del Prato S, Botros FT, et al. Effect of once weekly dulaglutide by baseline beta-cell function in people with type 2 diabetes in the AWARD programme. Diabetes Obes Metab. 2018;20:2023-8.

21. American Diabetes Association. 9. Pharmacologic approaches to glycemic treatment: standards of medical care in diabetes-2019. Diabetes Care. 2019;42:S90-102.

22. Singh S, Wright EE, Kwan AYM, et al. Glucagon-like peptide-1 receptor agonists compared with basal insulins for the treatment of type 2 diabetes mellitus: a systematic review and meta-analysis. Diabetes Obes Metab. 2017;19:228-38.
23. Levin PA, Nguyen H, Wittbrodt ET, Kim SC. Glucagon-like peptide-1 receptor agonists: a systematic review of comparative effectiveness research. Diabetes Metab Syndr Obes Targets Ther. 2017;10: 123-39.

24. Abd-El-Aziz MS, Kahle M, Meier JJ, Nauck MA. A meta-analysis comparing clinical effects of short- or long-acting GLP-1 receptor agonists versus insulin treatment from head-to-head studies in type 2 diabetic patients. Diabetes Obes Metab. 2017;19: 216-27.

25. Gallwitz B, Dagogo-Jack S, Thieu V, et al. Effect of once-weekly dulaglutide on glycated haemoglobin (HbA1c) and fasting blood glucose in patient subpopulations by gender, duration of diabetes and baseline HbA1c. Diabetes Obes Metab. 2018;20: 409-18.

26. Htike ZZ, Zaccardi F, Papamargaritis D, Webb DR, Khunti K, Davies MJ. Efficacy and safety of glucagon-like peptide- 1 receptor agonists in type 2 diabetes: a systematic review and mixed-treatment comparison analysis. Diabetes Obes Metab. 2017;19:524-36. 